\title{
Prostate Transglutaminase (TGase-4) Induces Epithelial- to-Mesenchymal Transition in Prostate Cancer Cells
}

\author{
RICHARD J. ABLIN ${ }^{1}$, SIONED OWEN ${ }^{2}$ and WEN G. JIANG ${ }^{2}$ \\ ${ }^{1}$ Department of Pathology, University of Arizona College of Medicine, \\ Arizona Cancer Center and BIO5 Institute, Tucson, AZ, U.S.A; \\ ${ }^{2}$ Cardiff China Medical Research Collaborative, Cardiff University School of Medicine, Cardiff, U.K.
}

\begin{abstract}
More men die with prostate cancer ( $\mathrm{PCa}$ ) than from it. However, once PCa is no longer organ-confined, it is associated with significant mortality. Epithelial-to-mesenchymal transition (EMT) is one mechanism facilitating progression in cancer. Our studies of transglutaminase-4 (TGase-4), a member of the TGase family, expressed in the prostate gland, have implicated it in the regulation of the invasive properties of $\mathrm{PCa}$. The present study investigated the role of TGase-4 on EMT of PCa cells. Materials and Methods: A panel of PCa cell lines: CA-HPV-10, PZ-HPV-7, PC-3 and DU-145 were used. An antiTGase-4 transgene was constructed to eliminate the expression of TGase-4 in CA-HPV-10 (positive for TGase-4). An expression construct for human TGase-4 was used to transfect PCa cells negative for TGase-4. The pattern of E-cadherin, $N$-cadherin and vimentin in these cells were evaluated using immunofluorescent staining. Cell motility was assessed using scratch wounding and ekectric cell-substrate impedance sensing (ECIS) assays. Results: Treatment of PZ-HPV-7 and CA-HPV10 cells with rhTGase-4 resulted in a significant increase in cell migration (1,407.9 $\Omega \pm 6.4 \Omega v s .1,691.2 \Omega \pm 8.3 \Omega$ in non-treated and rhTGase-4 treated cells, respectively, $p<0.01)$. Cells strongly expressing E-cadherin showed substantial changes of E-cadherin staining in that, after treatment with TGase-4, the intercellular staining of E-cadherin was diminished. Concomitantly, there was acquisition of $\mathrm{N}$-cadherin in TGase4-treated cells. Elimination of TGase-4 from CA-HPV-10 cells
\end{abstract}

Correspondence to: Dr. Richard J. Ablin, Department of Pathology, University of Arizona College of Medicine 1501 N. Campbell Avenue, P.O. Box 245043, Tucson, AZ 85724-5043 U.S.A. Tel: +1 520-6266283, Fax: +1 520-626-1027, e-mail: ablinrj@email.arizona.edu and Dr. Wen G. Jiang, Cardiff China Medical Research Collaborative, Cardiff University School of Medicine, Heath Park, Cardiff, CF14 4XN, U.K. Tel: +44 292068 7065, e-mail: jiangw@cf.ac.uk

Key Words: Prostate transglutaminase, prostate cancer, EMT, epithelial-mesenchymal transition, cell migration, cadherin switch. significantly decreased cell motility (128.1 $\Omega \pm 107.4 \Omega$ vs. 31.7 $\Omega \pm 26.2 \Omega$, in CA-HPV-10 control and CA-HPV-10/TGase-4 knockout cells). Knocking- out TGase-4 from CA-HPV-10 cells also resulted in substantial loss of $N$-cadherin in the cells. Conclusion: TGase-4 resulted in loss of E-cadherin/acquisition of $\mathrm{N}$-cadherin and cell migration indicating it is a keen regulator of EMT in prostate epithelia-derived cancer cells. In concert with its other properties involved in disease progression, the present observations suggest TGase-4 as a prospective marker of disease progression.

Prostate transglutaminase, also known as transglutaminase4 (TGase-4) belongs to the transglutaminases (EC 2.3.2.13 [TGases]) family of proteins $(1,2)$ and is expressed in a pattern different from other members of the TGase family. TGase-4 expression is restricted to the prostate gland $(3,4)$. The biological and pathological roles for TGase- 4 are not at all clear. In prostate cancer (PCa), TGase-4 expression remains controversial, with reports showing a possible differential expression in normal prostate epithelial cells and PCa cells $(5,6)$. However, these early studies were limited, particularly in the methodological approach utilized. The full implications of TGase-4 in PCa require further investigation.

The rat homologue of TGase-4, rat prostate TGase (or DP1) has been suggested to be responsible for the crosslinking during the copulatory plug formation and may be involved to some degree in sperm cell motility and immunogenicity $(7,8)$. There has been some recent interest in the biological role of TGase- 4 in PCa cells. TGase- 4 was found to be able to stimulate the invasiveness of PCa cells and assist tumor-endothelial interactions (9, 10). The terminology of epithelial- mesenchymal transition describes the events that convert adherent epithelial cells into individual migratory cells that can invade the extracellular matrix and has been collectively referred to as epithelial-tomesenchymal transition (EMT) $(11,12)$. At a biomedical and molecular level, EMT is characterized by such changes as the cadherin switch, loss of cytokeratin, increased expression 
Table I. Primer and oligo sequences for PCR, ribozyme and amplification of full coding sequence of prostate transglutaminase (TGase-4).

\begin{tabular}{|c|c|c|}
\hline & Sense $\left(5^{\prime}-3^{\prime}\right)$ & Anti-Sense ( $\left.5^{\prime}-3^{\prime}\right)$ \\
\hline TGase-4 expression & atgatggatgcatcaaaaga & ctacttggtgatgagaacaatcttctga \\
\hline TGase-4 ribozyme 1 & atgatggatgcatcaaaagag & ctacttggtgatgagaacaa \\
\hline TGase-4 ribozyme 1 & ctgcagtttggaactcccatgtgtggtgactgatgagtccgtgagga & actagttgaatcaggacaacgccgtttttcgtcctcacgga \\
\hline TGase-4 ribozyme 2 & ctgcagttcagttggtggtggtagctgatgagtccgtgagga & actagtccagcccctacaatttcgtcctcacggga \\
\hline TGase-4 (position 62) & atggatgcatcaaaagagc & $\begin{array}{l}\text { aggtgaaacacctgtcctc } \\
\text { actgaacctgaccgtacaaggtgaaacacctgtcctc, for Q-PCR)) }\end{array}$ \\
\hline TGase-4 (position 1957) & ataaaatgcacccaataaa & $\begin{array}{c}\text { ctacttggtgatgagaacaatc } \\
\text { (actgaacctgaccgtacatacttggtgatgagaacaatc, for Q-PCR) }\end{array}$ \\
\hline GAPDH & agcttgtcatcaatggaaat & cttcaccaccttcttgatgt \\
\hline GAPDH for Q-PCR & ctgagtacgtcgtggagtc & actgaacctgaccgtacacagagatgatgaccettttg \\
\hline$\beta$-actin & atgatatcgccgegctcg & cgctcgtgtaggatcttca \\
\hline
\end{tabular}

of vimentin and collagen, spindle-like morphology and gain of migration. EMT is widely involved in embryonic development and pathological conditions, and occurs during the progression of cancer (11). Mesenchymal-like cancer cells are associated with an aggressive phenotype (13).

Our recent studies and observations of cell morphology when TGase-4 expression was manipulated in $\mathrm{PCa}$ stimulated the present study in which we investigate the impact of TGase-4 on EMT in PCa cells.

\section{Materials and Methods}

Materials. Human PCa cell lines, PC-3, DU-145, CA-HPV-10, and PZ-HPV-7 were obtained from the ATCC (Manassas, VI, USA). Rabbit anti-human TGase-4 antibodies were obtained from ABCAM (Cambridge, UK), rat monoclonal anti-human TGase-4 was from Abnova (Taipei, Taiwan). Monoclonal anti-human E-cadherin and anti-vimentin were from Sigma-Aldrich (Little Chartfont, UK). Polyclonal anti-human N-cadherin, anti-CK19, monoclonal antiactin and anti-GAPDH were from Santa Cruz Biotechnologies Inc. (Santa Cruz, CA, USA). Full length recombinant human TGase-4 was from Abnova. All other chemicals were from Sigma-Aldrich, unless stated otherwise.

Creation of sublines of PCa cells in which TGase-4 transcripts were knocked down by way of ribozyme transgenes and by overexpressing TGase-4 in the cells. We created a set of sublines from prostate cancer cells in which the expression of TGase-4 transcript was knocked down by way of ribozyme transgenes, as recently reported (9). Briefly, using anti-human TGase4 ribozyme transgenes created recently, we established the following new sublines: TGase4 knock-down cells (designated here as CA-HPV-10 ${ }^{\Delta \text { TGase } 4}$ in this manuscript), plasmid only control cells (CA-HPV-10pEF6), and the wild type, CA-HPV-10WT. Similarly, using a human TGase-4 expression construct, we established stably transfected sublines: PC$3_{\mathrm{pEF} / \mathrm{His}}$ and $\mathrm{PC}-3^{\mathrm{TG} a s e} 4 \mathrm{exp}$, for control transfection and TGase-4 expression, respectively.

RNA preparation, RT-PCR and quantitative real-time PCR. RNA from cells was extracted using the Tri-reagent solution (Sigma-
Aldrich) and concentration quantified using a spectrophotometer (Wolf Laboratories, York, UK). PCR was performed using sets of primers (Table I). $\beta$-Actin was amplified and used as a house keeping control. PCR products were then separated on a $0.8 \%$ agarose gel, visualised under UV light, photographed using a Unisavetm camera (Wolf Laboratories, York, England, UK) and documented with Photoshop software. Real time PCR was conducted as we previously reported (14), using specific primers as shown in Table I.

In vitro cell growth assay. This was based on a previously reported method (14). In brief, cells were plated into 96-well plated at 2,000 cells/well followed by a period of incubation. Cells were fixed in $10 \%$ formaldehyde on the day of plating and daily for the subsequent 5 days and $0.5 \%$ crystal violet (w/v) was used to stain cells. Following washing, the stained crystal violet was dissolved with $10 \%(\mathrm{v} / \mathrm{v})$ acetic acid and the absorbance was determined at a wavelength of $540 \mathrm{~nm}$ using an ELx800 spectrophotometer. Absorbance represents the cell number.

Electric cell-substrate impedance sensing (ECIS)-based cell adhesion assay. Two models of ECIS instrument were used: ECIS 9600 (for screening) and ECIS1600R (for modelling). In both systems, 8W10E arrays were used (Applied Biophysics Inc, Troy, NY, USA) $(10,15) .300,000$ respective were added to each wells. Electric changes were continuously monitored for up to $24 \mathrm{hrs}$. In the 9600 system, the monitoring was at fixed $30 \mathrm{~Hz}$. In the $1600 \mathrm{R}$ system, two conditions were recorded: $400 \mathrm{~Hz}, 4,000 \mathrm{~Hz}, 40,000 \mathrm{~Hz}$ for screening the nature of endothelial changes and $4,000 \mathrm{~Hz}$ fixed frequency for cell modelling.

Immunofluorescence staining in cells and tissues. Cells were seeded in 16-well chamber slides and allowed to adhere overnight. After fixation with $5 \%$ formaldehyde, cells were treated with $0.2 \%$ Triton x 100 for $5 \mathrm{~min}$, before being incubated for $20 \mathrm{~min}$ in a $10 \%$ horse serum blocking solution. Cells were then probed with an appropriate primary antibody. Following extensive washings, sections were incubated for $30 \mathrm{~min}$ in the secondary FITC-and TRITC conjugated in the presence of Hoescht 33258 at $10 \mu \mathrm{g} / \mathrm{ml}$ (Sigma). Following extensive washings, the slides were mounted using Flurosave ${ }^{\mathrm{TM}}$ mounting media (Calbiochem, Nottingham, UK) and allowed to harden overnight at $4^{\circ} \mathrm{C}$, before being examined. Slides were 
examined using an Olympus fluorescence microscope and photographed using a Hamamatsu digital camera. The images were documented using the Cellysis software (Olympus).

Statistical analysis was carried out using Minitab. For normality test: Anderson-Darling test and for statistical difference Student's $t$ test.

\section{Results}

Expression of TGase-4 in PCa cells resulted in significant increase in cellular motility. Sublines from PC-3 (TGase-4negative, Figure 1) and CA-HPV-10 (strongly positive for TGase-4) cells were created. PC-3 cells over-expressed TGase-4, as shown by immunocytochemical analysis and analysis of gene transcripts (Figure 1). In CA-HPV-10 cells and using anti-TGase- 4 ribozyme transgenes, we knockeddown the expression of TGase-4 (Figure 1B and C). Using these new sublines, we compared the difference in cellular motility from their parent lines.

As shown in Figure 2A, and as previously reported, overexpression of TGase- 4 in PC-3 cells resulted in an increase in cell migration in comparison to control transfected cells. In contrast, CA-HPV-10 cells strongly positive for TGase-4 and with a limited degree of motility, migrated faster on loss of TGase-4 by way of ribozymes.

In order to evaluate the effects of exogenous TGase-4 on PCa cells, we used recombinant human (rh) TGase-4 directly on a panel of PCa cells. Shown in Figure 2 (B-D), in both PZ-HPV-7 and DU-145 cells which are negative for TGase4 as shown in previous study (9), rhTGase-4 resulted in an increase in cell migration.

Over-expression of TGase-4 in PCa cells resulted in reduction of E-cadherin in the cells. Here, the effect of whether treating the PZ-HPV-7 cells, that are positive for Ecadherin and largely negative for $\mathrm{N}$-cadherin, would cause any changes in the cell adhesion molecules were evaluated. DU-145 cells, weakly positive for E-cadherin, lost the staining of the cell adhesion molecule after treatment with rhTGase-4 (Figure 3). Shown in Figure 4, rhTGase-4 treatment rendered cells with far less E-cadherin staining in comparison with non-treated cells (right panel). Interestingly and concomitantly, there appears to be an increase in $\mathrm{N}$ cadherin staining in the cells (left panel, Figure 4).

Knocking-down TGase-4 in CA-HPV-10 cells and the resulting changes in $N$-cadherin and vimentin. To further evaluate the relationship between TGase- 4 and EMT, we used the CA-HPV-10 cell model created in the study (Figure 1) in which we knocked-down the expression of TGase-4. Shown in Figure 4, after loss of TGase-4, there were increased staining for $\mathrm{N}$-cadherin and vimentin, markers for mesenchymal cells, in the cytosol of the cells. The same was seen with PZ-HPV-7 cells.

\section{Discussion}

Prostate transglutaminase, TGase-4, is a protein uniquely expressed in the prostate gland, but with little biological functions assigned to the molecule. In the present study, we have provided evidence for the first time that TGase- 4 is a protein important to the EMT process in PCa cells.

TGase- 4 has recently been shown to be able to regulate the invasiveness and migratory property of PCa cells $(9,10)$. In these previous studies, it has been shown that a gain of TGase-4 in PCa cells resulted in an increase in the migration speed and invasiveness of PCa cells. Vice versa, loss of TGase- 4 correlates with the decrease of motility of the cells, an observation further made within the present study. In concert with changes of cell morphology following the change of TGase- 4 in the cells, are characteristics of the hallmark of EMT in cells. The present study has provided much needed support to confirm the occurrence of EMT in the PCa cells, after expression of TGase-4. Our data has shown that both over-expressing TGase-4 in PCa cells and treatment of PCa cells with exogenous TGase- 4 resulted in a loss of E-cadherin in the cells, and to some degree an increase in N-cadherin, a cadherin switch. Thus, it is clear that high levels of TGase-4 are associated with the biochemical and molecular markers indicative of EMT in the cells.

Agents/molecules regulating EMT in PCa cells are rather hard to come by. Zhu and Kyprianou (16) have shown that androgen is able to induce EMT in PCa cells. The same has been reported for IGF-I and by induction of FGFR1 $(17,18)$. It is very interesting to note, however, that some of the prostate-specific proteins, namely kallikrein 4 and kallikrein3 (PSA) are also regulators of EMT in PCa cells (19). Thus, TGase-4 may well act as a powerful EMT-inducer in the host, similar to that observed with PSA in the induction of EMT and tumour progression in PCa.

Although the present study is the first to report the effect of a prostate-specific TGase on the EMT of PCa cells, it has been recently reported that TGase, namely TGase-2 is able to induce EMT in cancer cells $(20,21)$. In these studies, and similar to the findings reported here, TGase- 2 has been found to induce loss of E-cadherin in mammary epithelial cells and ovarian cancer cells. It is also interesting to note that TGase2 alone is sufficient to induce EMT, again similar to TGase4. Thus, it appears that TGases, at least TGase- 2 and TGase4 , are commonly involved in the regulation of EMT.

A number of transcription factors including snail, twist, ZEB1 and slug are known to induce EMT in PCa cells, by regulating the expression of the cadherins (22-24). It will be useful to investigate the potential effect of TGase- 4 on these factors in PCa cells. The therapeutic value of targeting EMTrelated cellular and molecular events has been proposed in recent years. Although, TGase- 4 in the present and previous studies have been demonstrated to be a factor associated with 

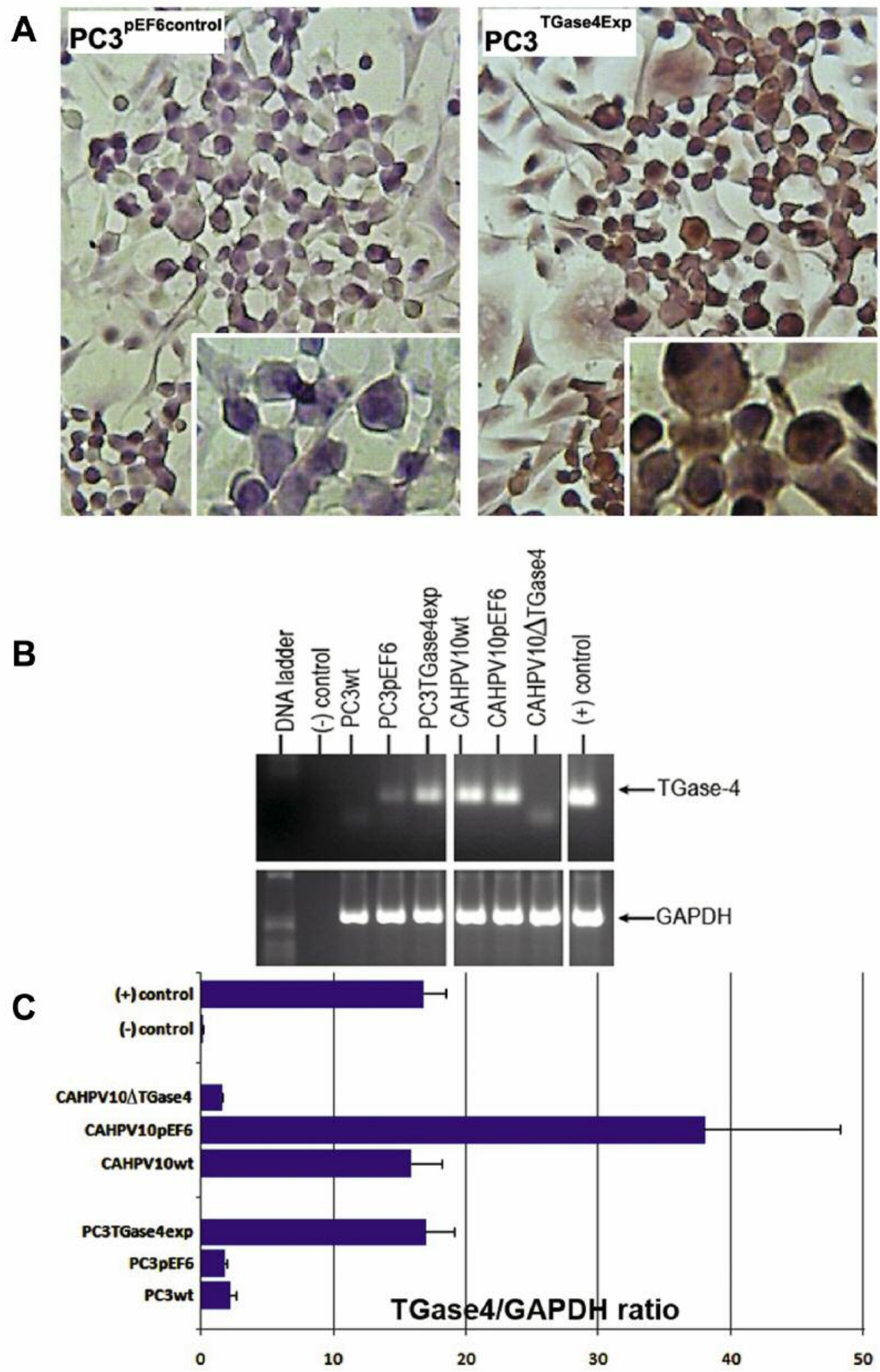

Figure 1. Creation of prostate cancer sublines with differential expression of TGase-4. A: over-expression of TGase-4 in PC-3 cells after transfection as shown by immunocytochemical staining of control vs. transfected cells. B and C: Qualitative $(B)$ and quantitative $(C)$ analysis of TGase-4 transcripts in PC-3 and CA-HPV-10 cells, after transfection. 

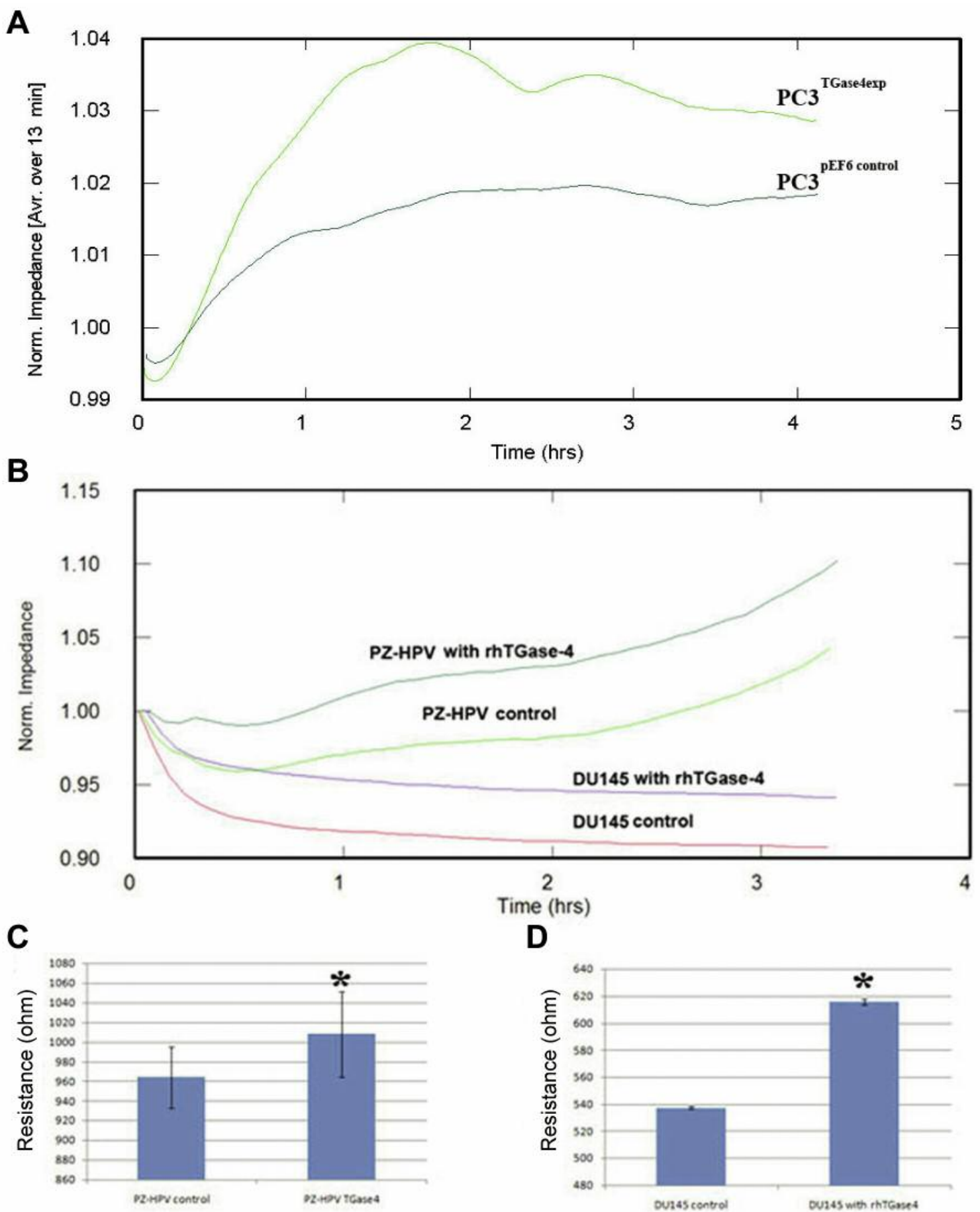

Figure 2. A: Expression of TGase-4 and the pace of cell migration as determined by ECIS. Shown are PC-3 cells transfected with a control plasmid and those with TGase-4 expression construct. Cells over-expressing TGase-4 had a marked increase in migration. B, C and D: The effects of rhTGase4 on the migration of prostate cancer cells. B: traces of the cell migration after wounding (time-0) showing the normalised impedance of the cells. $C$ and D: Cellular motility after cells being treated by rhTGase-4 as in A. Shown are resistance following Rb modelling. ${ }^{*} p<0.05$ vs. no treatment control.

aggressiveness of $\mathrm{PCa}$ cells, the clinical implication of TGase-4 in patients with PCa is yet to be fully established. In this regard, preliminary comparative immunohistochemical study of normal and malignant human prostate tissues have shown an increase in TGase-4 in association with the Gleason score (25). 

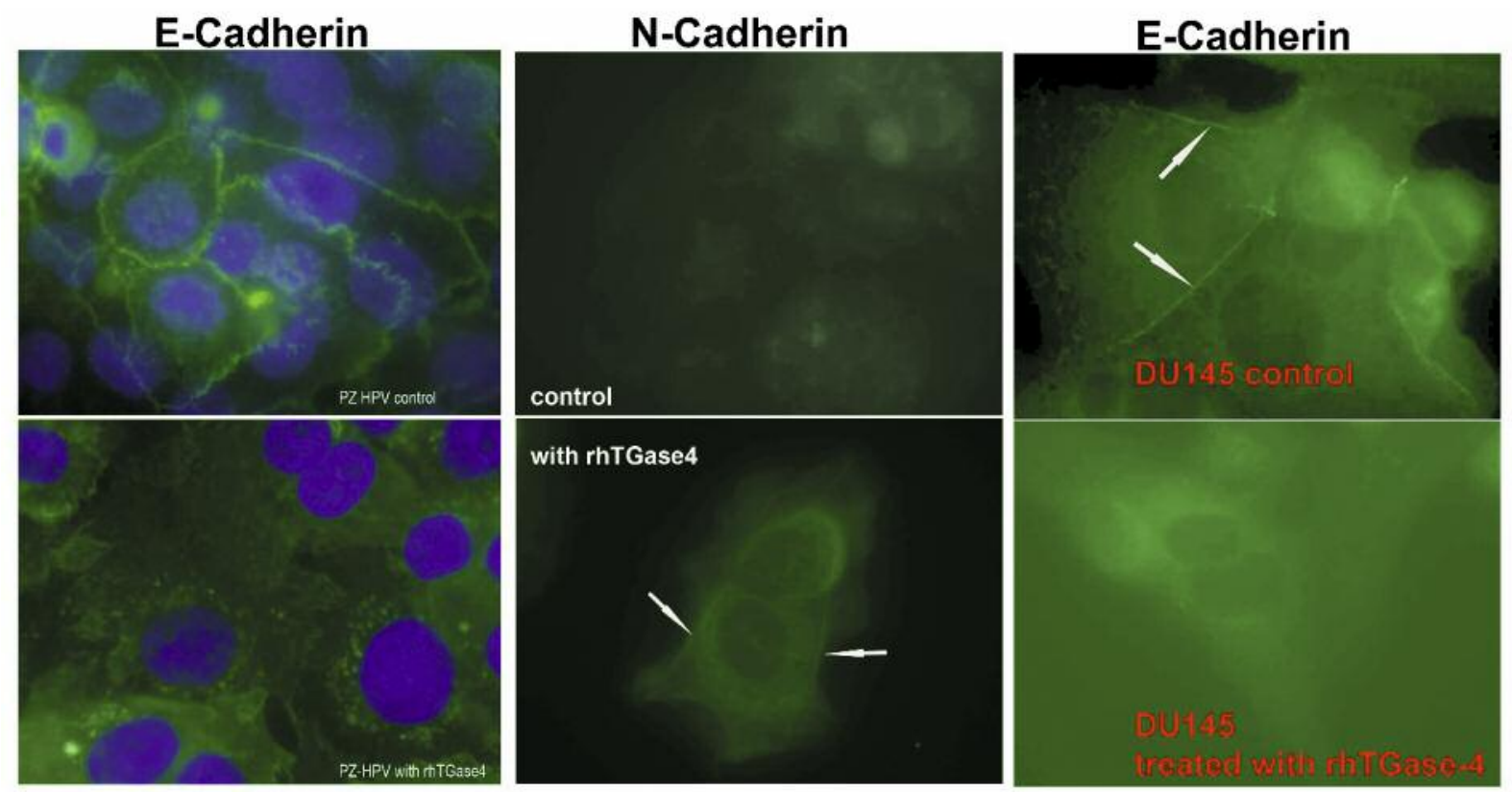

Figure 3. Treatment of prostate cancer cells with rhTGase-4 resulted in N-cadherin/E-cadherin shift. Left and middle panel are PZ-HPV-7 cells and right panel are DU-145 cells. Top panels are control and bottom panels are cells treated with rhTGase-4. Arrows indicate cadherin staining.
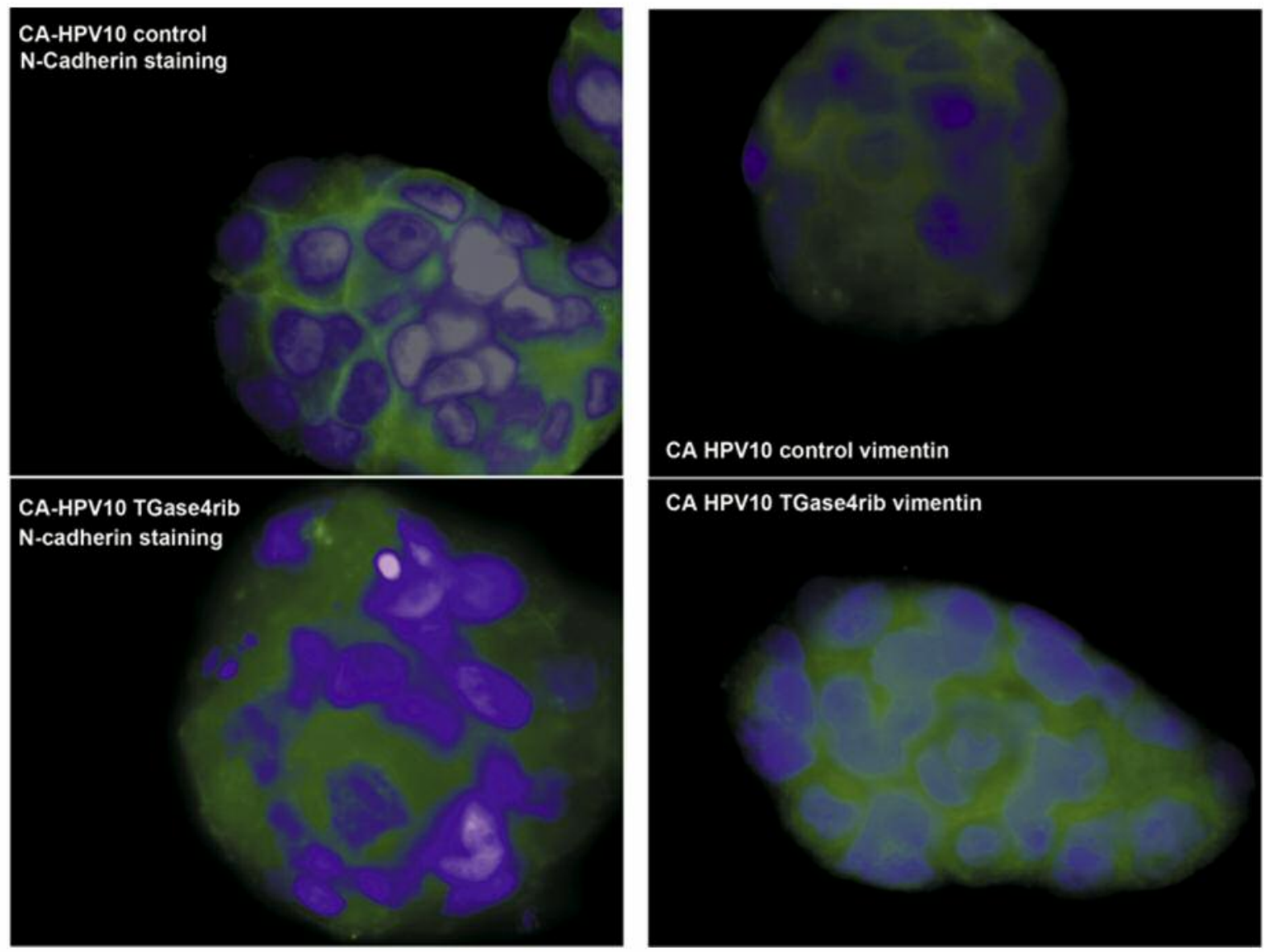

\section{CA HPV10 TGase4rib vimentin}

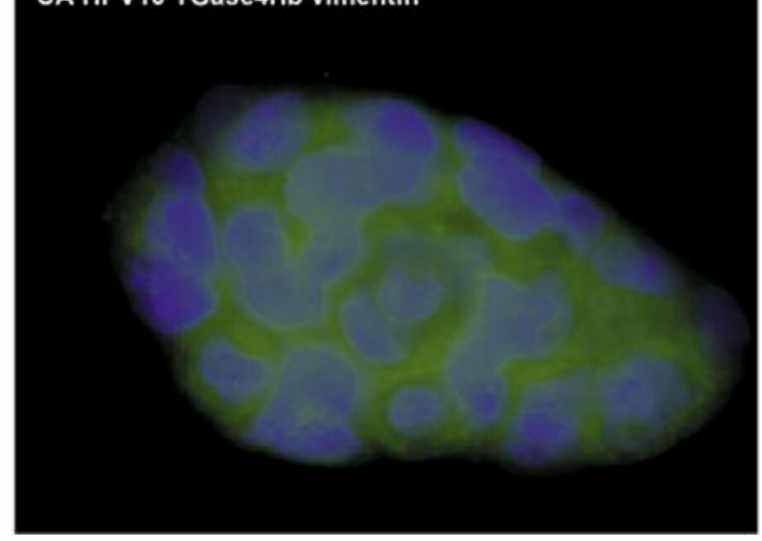

Figure 4. Knocking-down TGase-4 from CA-HPV-10 cells resulted in changes in reduction of $N$-cadherin from the cells (bottom). Left: $N$-cadherin; right: vimentin staining. TGase-4rib: anti-TGase4 ribozyme transgene transfected cells. 
In conclusion, TGase-4, a protein enzyme unique to the prostate gland, is associated with the invasive and migratory properties of PCa cells. It induces biochemical and molecular events leading to the conclusion that it is a inducer of the EMT in PCa cells.

\section{Acknowledgements}

The Authors wish to thank Cancer Research Wales, Robert Benjamin Ablin Foundation for Cancer Research, and Albert Hung Foundation for supporting their work. Dr. Sioned Owen was supported by the Life Sciences National Research Network Wales (LSRNW/Ser Cymru).

\section{References}

1 Folk JE: Transglutaminases. Annu Rev Biochem 49: 517-531, 1980.

2 Gentile V, Grant FJ, Porta R and Baldini A: Localization of the human prostate transglutaminase (type IV) gene (TGM4) to chromosome 3p21.33-p22 by fluorescence in situ hybridization. Genomics 27: 219-220, 1995.

3 Dubbink HJ, de Waal L, van Haperen R, Verkaik NS, Trapman $\mathrm{J}$ and Romijn JC: The human prostate-specific transglutaminase gene (TGM4): genomic organization, tissue-specific expression, and promoter characterization. Genomics 51: 434-444, 1998.

4 Grant FJ, Taylor DA, Sheppard PO, Mathewes SL, Lint W, Vanaja E, Bishop PD and O'Hara PJ: Molecular cloning and characterization of a novel transglutaminase cDNA from a human prostate cDNA library. Biochem Biophys Res Commun 203: 1117-1123, 1994.

5 An G, Meka CS, Bright SP and Veltri RW: Human prostatespecific transglutaminase gene: promoter cloning, tissue-specific expression, and down-regulation in metastatic prostate cancer. Urology 54: 1105-1111, 1999.

6 Dubbink HJ, Hoedemaeker RF, van der Kwast TH, Schroder FH and Romijn JC: Human prostate-specific transglutaminase: a new prostatic marker with a unique distribution pattern. Lab Invest 79: 141-150, 1999.

7 Ablin RJ and Whyard TC: Identification and possible biological relevance of spermatozoal transglutaminase. Experientia 47: 277-279, 1991.

8 Williams-Ashman HG: Transglutaminases and the clotting of mammalian seminal fluids. Mol Cell Biochem 58: 51-61, 1984.

9 Davies G, Ablin RJ, Mason MD and Jiang WG: Expression of the prostate transglutaminase (TGase-4) in prostate cancer cells and its impact on the invasiveness of prostate cancer. J Exp Ther Oncol 6: 257-264, 2007.

10 Jiang WG, Ablin RJ, Kynaston HG and Mason MD: The prostate transglutaminase (TGase-4, TGaseP) regulates the interaction of prostate cancer and vascular endothelial cells, a potential role for the ROCK pathway. Microvasc Res 77: 150-157, 2009.

11 Baum B, Settleman J and Quinlan MP: Transitions between epithelial and mesenchymal states in development and disease. Semin Cell Dev Biol 19: 294-308, 2008.

12 Bolender DL and Markwald RR: Epithelial-mesenchymal transformation in chick atrioventricular cushion morphogenesis. Scan Electron Microsc: 313-321, 1979.
13 Zeisberg $M$ and Neilson EG: Biomarkers for epithelialmesenchymal transitions. J Clin Invest 119: 1429-1437, 2009.

14 Ye L, Kynaston H and Jiang WG: Bone morphogenetic protein10 suppresses the growth and aggressiveness of prostate cancer cells through a Smad independent pathway. J Urol 181: 27492759, 2009 .

15 Keese CR, Wegener J, Walker SR and Giaever I: Electrical wound-healing assay for cells in vitro. Proc Natl Acad Sci USA 101: 1554-1559, 2004.

16 Zhu ML and Kyprianou N: Role of androgens and the androgen receptor in epithelial-mesenchymal transition and invasion of prostate cancer cells. FASEB J 24: 769-777, 2010.

17 Acevedo VD, Gangula RD, Freeman KW, Li R, Zhang Y, Wang F, Ayala GE, Peterson LE, Ittmann $M$ and Spencer DM: Inducible FGFR-1 activation leads to irreversible prostate adenocarcinoma and an epithelial-to-mesenchymal transition. Cancer Cell 12: 559-571, 2007.

18 Graham TR, Zhau HE, Odero-Marah VA, Osunkoya AO, Kimbro KS, Tighiouart M, Liu T, Simons JW and O'Regan RM: Insulin-like growth factor-I-dependent up-regulation of ZEB1 drives epithelial-to-mesenchymal transition in human prostate cancer cells. Cancer Res 68: 2479-2488, 2008.

19 Veveris-Lowe TL, Lawrence MG, Collard RL, Bui L, Herington AC, Nicol DL and Clements JA: Kallikrein 4 (hK4) and prostate-specific antigen (PSA) are associated with the loss of E-cadherin and an epithelial-mesenchymal transition (EMT)-like effect in prostate cancer cells. Endocr Relat Cancer 12: 631-643, 2005.

20 Kumar A, Xu J, Brady S, Gao H, Yu D, Reuben J and Mehta K: Tissue transglutaminase promotes drug resistance and invasion by inducing mesenchymal transition in mammary epithelial cells. PLoS One 5: e13390, 2010.

21 Shao M, Cao L, Shen C, Satpathy M, Chelladurai B, Bigsby RM, Nakshatri $H$ and Matei D: Epithelial-to-mesenchymal transition and ovarian tumor progression induced by tissue transglutaminase. Cancer Res 69: 9192-9201, 2009.

22 Beach S, Tang H, Park S, Dhillon AS, Keller ET, Kolch W and Yeung KC: Snail is a repressor of RKIP transcription in metastatic prostate cancer cells. Oncogene 27: 2243-2248, 2008.

23 Drake JM, Strohbehn G, Bair TB, Moreland JG and Henry MD: ZEB1 enhances transendothelial migration and represses the epithelial phenotype of prostate cancer cells. Mol Biol Cell 20: 2207-2217, 2009.

24 Wallerand H, Robert G, Pasticier G, Ravaud A, Ballanger P, Reiter RE and Ferriere JM: The epithelial-mesenchymal transition-inducing factor TWIST is an attractive target in advanced and/or metastatic bladder and prostate cancers. Urol Oncol 28: 473-479, 2010

25 Jiang WG, Ye L, Ablin RJ, Kynaston HG and Mason MD: The prostate transglutaminase (TGase-4) regulates the cellular response to hepatocyte growth factor like protein (HGFL) in prostate cancer cells. In: AACR Annual Meeting. Denver, Colarado: Proc Am Ass Cancer Res, p. 5507, 2009.

Received December 15, 2016

Revised January 10, 2017

Accepted January 12, 2017 